\title{
Investigando concepções sobre o papel de mediador ou transmissor sobre o papel de mediador ou transmissor de conhecimento na perspectiva de discentes do curso de letras-inglês
}

\author{
Carlos Eduardo Alves Lopes ${ }^{1}$
}

\begin{abstract}
Resumo. A linguagem, de acordo com a teoria sociocultural, é uma ferramenta extremamente importante para o processo de ensino/aprendizagem de línguas estrangeiras, uma vez que ela é, ao mesmo tempo, mecanismo de comunicação e de cognição (SWAIN \& LAPKIN, 1998). Diversos estudos apontam que o uso da linguagem, ou seja, a interação, deve ser maximizado durante as aulas de línguas estrangeiras para que, de fato, o aprendiz alcance seu objetivo com a língua-alvo. Todavia, Figueiredo (2006) aponta que há uma grande centralidade no discurso do professor. Hall e Walsh (2002) postulam que o modo como professores interagem com seus aprendizes tem uma grande influência nos papéis que tais profissionais exercerão no contexto de ensino. Professores que centralizam o discurso produzido em sala de aula neles mesmos tem a tendência de serem transmissores de conhecimento, enquanto aqueles que maximizam a oportunidade de fala de seus alunos, normalmente, se veem como mediadores do conhecimento. Neste trabalho, nos propomos a investigar a concepção de futuros professores de língua inglesa acerca de seu papel de mediador ou transmissor em relação ao ensino/aprendizagem, assim como averiguar se suas concepções dialogam com o que é proposto pela teoria sociocultural, já que os participantes são discentes do último ano do estágio supervisionado do curso de Letras-Inglês da Universidade Federal de Goiás-Jataí. Os resultados da análise de dados sugerem que os participantes da pesquisa apresentam noções acerca do que é ser professor transmissor assim como o que é ser mediador, que dialogam com o que é proposto pela teoria sociocultural e que a Universidade, mais especificamente o curso de Letras-Inglês, tem sido responsável pela formação de tais concepções.
\end{abstract}

Palavras-chaves: Teoria sociocultural. Papel dos professores de línguas. Mediador de conhecimento.

\section{Investigating conceptions about the role of mediator or transmitter of knowledge in the perspective of students from letras-inglês course.}

\begin{abstract}
Language, according to sociocultural theory, is an extremely important tool for the teaching/learning process of foreign languages, since it is both a communication and cognition mechanism (SWAIN \& LAPKIN, 1998). Several studies point out that the use of language, that is, interaction, should be maximized during foreign language classes so that the learner actually reaches his goal with the target language. However, Figueiredo (2006) points out that there is a great centrality in the teacher's discourse. Hall and Walsh (2002) postulate that the way teachers interact with their learners has a great influence on the roles that such professionals will play in the teaching context. Teachers who centralize the discourse produced in the classroom in themselves tend to be transmitters of knowledge, while those who maximize the speech opportunity of their students usually see themselves as mediators of knowledge. In this study, we aim to investigate the conception of future English teachers about their role as mediator or transmitter in relation to teaching/learning. We also aim to investigate if their conceptions dialogue with what is proposed by sociocultural theory, since the participants are students
\end{abstract}

\footnotetext{
${ }^{1}$ Mestrando. Faculdade de Letras. Programa de Pós-Graduação Letras e Linguística, Universidade Federal de Goiás. karlosdoodoo@ hotmail.com
} 
are inserted into an English teacher training program of the Federal University of Goiás - Jataí. The results of the data analysis suggest that the participants of the research present notions about what it is to be a transmitting teacher as well as what it is to be a mediator. It also suggest that they dialogue with what is proposed by sociocultural theory and that the University, more specifically their teacher training program, has been responsible for the formation of such conceptions.

Keywords: Sociocultural theory. The role of language teachers. Mediator of knowledge.

\section{INTRODUÇÃ̃O}

De acordo com a teoria sociocultural, a linguagem é uma importante ferramenta no processo de ensino/aprendizagem de línguas estrangeiras, pois ao mesmo tempo que ela é utilizada como mecanismo de comunicação, ela é fundamental para os processos cognitivos do ser humano (SWAIN; LAPKIN, 1998, p. 319). Diversos estudos (HALL; WALSH, 2002; FIGUEIREDO, 2006; OXFORD, 1997) apontam que, dentro do contexto aqui mencionado, professores devem maximizar as oportunidades de uso da linguagem para que os alunos interajam e aprendam de fato um outro idioma. No entanto, de acordo com Figueiredo (2003, p. 125), pesquisas têm demonstrado que há uma grande centralidade no discurso do professor, pois é ele quem "geralmente, seleciona o tópico da conversação, determina quem fala e é quem faz a maior parte das perguntas".

Hall e Walsh (2002), em um estudo que discute os tipos de interação usados entre professores e alunos no ensino/aprendizagem de uma língua estrangeira, apontam dois modos: O IRE (Iniciation-Response-Evaluation) e o IRF (Iniciation-Response-Follow Up). O primeiro se relaciona ao modo como professores interagem com alunos iniciando uma conversa, esperando a resposta dos alunos e posteriormente a avaliando de forma limitada com um "muito bom!", "correto" ou "esta não é a resposta correta". Já o segundo modo é bem similar ao primeiro, diferenciando apenas no modo de avaliação. No IRF, o professor problematiza a resposta do aluno, ao invés de limitá-la, fazendo com que o aprendiz reflita, discuta e crie hipóteses sobre o tópico abordado, aumentando, assim, as oportunidades de fala dos alunos.

Os autores supracitados, no parágrafo anterior, ainda afirmam que o uso de determinados padrões de interação entre professores e alunos está diretamente ligado à crença dos primeiros em relação ao que eles entendem por ensinar e aprender, pois professores que enxergam seus alunos como agentes ativos no processo de aprendizagem, tendem a usar mais IRF. Entretanto, aqueles que se veem como autoridade e transmissores de conhecimento 
utilizam mais o IRE. Percebemos, então, que o tipo de interação existente entre professor e aluno está relacionado ao modo como tais profissionais enxergam seu papel.

Pensando no que acaba de ser exposto, investigar a concepção de professores de línguas em relação à sua função parece-nos de extrema importância, uma vez que ela exercerá forte influência sobre a prática pedagógica dos mesmos. Sendo assim, o presente artigo almeja investigar qual a visão de futuros professores de língua inglesa acerca de seu papel de mediador ou transmissor de conhecimento, assim como averiguar se suas concepções dialogam com o que é proposto pela teoria sociocultural, já que os participantes deste estudo são discentes do último ano do estágio supervisionado do curso de Letras-Inglês da Universidade Federal de Goiás-Jataí

\section{FUNDAMENTAÇÃO TEÓRICA}

\subsection{Linguagem como ferramenta psicológica}

Lantolf e Appel (1994) apontam que, para Vygotsky, o homem, em conjunto com outros, sempre teve a necessidade de utilizar ferramentas mecânicas para controlar e dominar a natureza. Tais ferramentas sempre são externamente orientadas para a mudança de um objeto (VYGOTSKY, p. 55, 1987). Ou seja, a interação entre o homem e o mundo sempre foi e sempre será mediada por algum tipo de ferramenta que, na perspectiva do teórico, irá facilitar suas atividades.

Fazendo analogia às ferramentas mecânicas, Vygotsky defende a existência de ferramentas psicológicas, mencionando símbolos algébricos, diagramas, esquemas e a linguagem, que, em sua visão, seriam artefatos mediadores da atividade mental do homem. Neste sentido, para o pesquisador, do mesmo modo que o indivíduo utiliza ferramentas para manipular e controlar o espaço físico, ele também faz uso das ferramentas psicológicas para controlar suas atividades mentais e físicas.

Ao contrário das ferramentas concretas que mudam os objetos externamente, as ferramentas psicológicas, principalmente a linguagem tem uma natureza interna capaz de provocar mudanças em outros ou, até mesmo, no próprio indivíduo. 
A função do instrumento é servir como um condutor da influência humana sobre o objeto da atividade; ele é orientado externamente; deve necessariamente levar a mudanças nos objetos. Constitui um meio pelo qual a atividade humana externa é dirigida para o controle e domínio da natureza. O signo, por outro lado, não modifica em nada objeto da operação psicológica. Constitui um meio da atividade interna dirigido para o controle do próprio indivíduo; o signo é orientado internamente. Essas atividades são tão diferentes uma da outra, que a natureza dos meios por elas utilizados não pode ser a mesma. (VYGOSTKY, 1991, p. 40)

De acordo com Lantolf e Appel (1994, p. 8), quando a linguagem é utilizada em determinada atividade, a ferramenta psicológica é capaz de modificar "o processo e a estrutura de funções mentais utilizadas na atividade.”. Os autores concordam com a perspectiva vygotskyana de que "o uso de meios artificiais - a transição para a atividade mediada - muda, fundamentalmente, todas as operações psicológicas [...]" (VYGOSTKY, 1991, p.40). Nesse sentido, a linguagem só adquire o status de ferramenta psicológica quando ela serve de instrumento mediador para a modificação daquilo que Vygotsky nomeou como funções psicológicas superiores. Para que estas mudanças ocorram, é necessário que o indivíduo passe por um processo chamado de internalização. De acordo com o teórico, o processo não ocorre em forma circular, mas sim em espiral, uma vez que é necessária a passagem do desenvolvimento "por um mesmo ponto a cada nova revolução, enquanto avança para um nível superior". (VYGOTSKY, 1991, p. 40)

Vygotsky (1991, p. 40) definiu internalização como a "reconstrução interna de uma operação externa”. Segundo o teórico, a internalização acontece em uma série de acontecimentos.

a) Primeiramente, uma operação externa começa a ser reconstruída internamente sendo ela mediada pela linguagem;

b) Um processo interpessoal se transforma em intrapessoal, ou seja, "primeiro, no nível social, e, depois, no nível individual; primeiro, entre pessoas (interpsicológica), e, depois, no interior da criança (intrapsicológica)" (VYGOTSKY, 1991, p.40);

c) O processo previamente citado leva uma série de acontecimentos ao longo do desenvolvimento;

É nítida a importância dada ao externo, mais especificamente, ao social, sendo a linguagem a ferramenta utilizada, através da interação, para que o desenvolvimento ocorra. Para explicar como acontece o desenvolvimento, Vygotsky postula o conceito de Zona de Desenvolvimento Proximal (ZDP). 
$\mathrm{O}$ autor defende a ideia de que o indivíduo carrega consigo conhecimentos sóciohistoricamente construídos muito antes de entrarem na escola, uma vez que a partir do momento que a criança entra em contato com o mundo, ela já está aprendendo e, portanto se desenvolvendo. A este tipo de conhecimento já construído, Vygotsky (1991, p. 57) deu o nome de nível de desenvolvimento real que, em suas palavras, seria "o nível de desenvolvimento das funções mentais da criança que se estabeleceram como resultado de certos ciclos de desenvolvimento já completados". A ZDP seria, então, a distância entre esse nível de conhecimento acumulado pelo indivíduo com o nível de desenvolvimento potencial, "determinado através da solução de problemas sob a orientação de um adulto ou em colaboração com companheiros mais capazes".

Portanto, percebemos que, dentro da teoria sociocultural, a linguagem é uma ferramenta muito importante, pois: a) assim como as ferramentas mecânicas, ela também é mediadora da relação entre homem e mundo; b) ao contrário das ferramentas mecânicas que alteram o objeto externamente, a linguagem altera as funções psicológicas superiores internamente. c) essa alteração ocorre através de processos que passam do interpsicológico para o intrapsicológico; d) a interação social é primordial para a aprendizagem e consequentemente o desenvolvimento.

Sendo assim, podemos concluir que aprender um outro idioma é uma atividade metalinguística, pois aprendemos uma língua através da linguagem e, sendo assim, quanto mais oportunidades de interação, nós, professores de LE priorizarmos para nossos alunos, mais eficaz será o desenvolvimento linguístico deles.

\subsection{O papel do professor na perspectiva da teoria sociocultural}

Tradicionalmente, o professor era visto como um detentor de conhecimento cuja função primordial seria sua transmissão de forma sistemática. Se questionarmos o porquê de tal concepção poderemos encontrar uma resposta na investigação sobre formação docente feita por Pereira (1999). De acordo com o autor, os cursos de formação de professores, ou seja, as licenciaturas, são frutos do modelo da racionalidade técnica adotado em nosso país na década de 30. Tal modelo era baseado em um método denominado " $3+1$ " no qual as disciplinas pedagógicas teriam duração de um ano enquanto as de conhecimentos específicos três. Sendo assim, o foco das licenciaturas era formar professores dominantes de conteúdo. 
O foco tecnicista das licenciaturas sofreu diversas críticas, dentre elas a separação entre teoria e prática e a crença de que um bom professor é aquele que domina apenas o conhecimento específico da área que irá lecionar. No modelo, o docente é visto como "um técnico, um especialista, que aplica com rigor, na sua prática cotidiana, as regras que derivam do conhecimento cientifico e do conhecimento pedagógico" (PEREIRA, 1999,p.112). Ou seja, o professor é concebido como um aplicador, transmissor daquilo que aprendeu na academia. Ele ensina o que aprendeu e não a aprender.

Volpi (2008), falando sobre o tradicionalismo no ensino de línguas, alega que o professor se limitava à aplicação de métodos ou à utilização de materiais didáticos que serviriam como fonte primordial de conhecimento. Neste sentido, toda responsabilidade do processo de aprendizagem ficaria para o professor, enquanto o aprendiz era visto como um agente passivo pronto para receber toda carga de conhecimento transmitida pelo seu mestre. No entanto, Paiva (2008, p. 134) afirma que houve o surgimento de uma nova visão sobre a função docente na qual “o professor há de ser um indivíduo consciente de que ele não é o detentor do monopólio do saber". Seu papel dentro desta concepção seria o de um compartilhador de responsabilidades onde tanto o professor quanto o aluno são agentes ativos no processo de ensino/aprendizagem. Percebemos, então, que a concepção de professor, dentro das atuais perspectivas, dá ao aprendiz uma nova função. Weininger (2008, p. 63) diz que o aluno "não poderá ficar mais no papel passivo de cruzar os braços e 'consumir' a aula do professor como se fosse um programa de TV".

Em sintonia com a perspectiva mencionada acima, Anton (1999) postula que as metodologias baseadas no ensino comunicativo de línguas sugerem um benefício ao se prezar um ambiente de aprendizagem no qual o discurso dos alunos seja enfatizado, contrariando, assim, o ensino tradicional focado na fala dos professores. A autora argumenta que nas salas de aula onde professores são vistos como autoridades e o conhecimento é transmitido, a interação professor-aluno é mínima e sempre voltada ao mestre. A pesquisadora defende a abordagem comunicativa, pois esta centraliza os aprendizes em diversos modos como: um currículo que preza suas necessidades, atividades que maximizem a oportunidade de interação e uma mudança no papel do professor que, agora, deve agir como um mediador no processo de comunicação. Nesse sentido, cabe ao professor maximizar as oportunidades de interação entre os alunos para que eles aprendam, uma vez que na visão de Van Lier (1991), tanto a interação quanto a participação e a negociação de significados criam oportunidades de aprender um outro idioma. 
Dentro dessa perspectiva de professor como mediador da aprendizagem, o profissional do ensino é o que Vygotsky denominou como o par mais experiente na construção de conhecimento dentro da ZDP. Ele deve mediar os momentos de interação da sala de aula oferecendo scaffolding. Fazendo analogia a um andaime, estrutura utilizada como apoio em construções, Wood, Bruner e Ross (1976, p. 90) definem o processo como "essencialmente o adulto controlando aqueles elementos da tarefa que são, inicialmente, além da capacidade do aprendiz, assim permitindo que ele concentre-se e complete apenas tais elementos que estão dentro da sua competência.”. Em outras palavras, scaffolding seriam estratégias de apoio utilizadas pelo professor para mediar o processo de aprendizagem do aluno.

Anton (1999) defende que, apesar de os conceitos de ZDP e Scaffolding terem sido, originalmente, desenvolvidos a partir de estudos sobre a aprendizagem infantil, tais postulações se aplicam a situações de aprendizagem de uma segunda língua.

Figueiredo (2006) afirma que, na teoria vygotskyana, há uma ênfase muito grande no papel do adulto como par mais desenvolvido mediando o processo de aprendizagem no par com menos experiência. Entretanto, autores como Wells (1999) e Swain, Brooks e Tocalli-Beller (2002) defendem que o par mais capaz nem sempre será um adulto, pois na interação aprendizaprendiz pode haver convergências de ideias, apontamentos para soluções e questionamentos que poderão servir como apoio para a aprendizagem.

Neste sentido, a teoria sociocultural centra-se muito no papel da aprendizagem cooperativa e colaborativa. Oxford (1997) revela que muitos autores usam os dois termos como equivalentes, no entanto, a autora aponta diferenças entre os dois construtos. Para ela, a aprendizagem cooperativa é mais estruturada, com uma ênfase maior nas técnicas do professor com as quais ele conduz os alunos a trabalharem em grupos para alcançarem algum objetivo. Já a aprendizagem colaborativa é mais livre, menos prescritiva e mais focada na co-construção de conhecimento entre os aprendizes.

Figueiredo (2006), corroborando as afirmações da autora, diz que na aprendizagem cooperativa há uma ênfase maior na tarefa, enquanto na colaborativa destaca-se a co-construção da aprendizagem. $\mathrm{O}$ autor, reconhecendo tais diferenças, enfatiza que a importância de ambas está no fato de que elas maximizam a oportunidade de interação entre os aprendizes. Quando a aprendizagem é centrada na interação, há mudanças nos papéis tradicionais de professor e aluno. O primeiro é visto como mediador da aprendizagem, já o segundo assume uma função mais ativa que faz com que eles "tornem-se responsáveis pela maneira de dar termo a uma atividade" (FIGUEIREDO, 2006 p. 23). Sendo assim, percebemos um grande diálogo entre as 
concepções de Figueiredo (2006) com o que foi apontado por Weininger (2008) e Paiva (2008) anteriormente.

Podemos concluir, então, que um ensino tradicional focado na transmissão de conhecimento não se mostra eficaz, uma vez que ele não maximiza as oportunidades de interação em sala de aula. Ao invés disso, as atuais perspectivas, principalmente dentro da Linguística Aplicada, enfatizam o professor como um mediador do conhecimento, maximizando as oportunidades de interação na sala de aula, pois conforme concluem Swain \& Lapkin (1998), nos utilizamos a linguagem para a construção da própria linguagem.

\section{OBJETIVOS}

Para o presente trabalho, temos como objetivo principal investigar a visão que futuros professores de línguas, especificamente o Inglês, tem acerca de seu papel enquanto mediador ou transmissor.

Como específicos, temos:

- Indagar a concepção que os participantes possuem em relação a professor transmissor e professor mediador;

- Questionar qual das concepções é enfatizada ao longo da graduação;

- Apurar com qual das perspectivas atuam ou pretendem atuar;

- Averiguar se suas concepções dialogam com o que é proposto pela teoria sociocultural;

\section{METODOLOGIA}

Para o presente trabalho, escolhemos como modo de investigação qualitativa o estudo de caso. De acordo com Hartley (1994), tal estratégia de pesquisa trata-se de uma investigação minuciosa, muitas vezes acompanhada por coleta de dados dentro de um delimitado período de tempo em um contexto específico no qual esse influencia e é influenciado pelo objeto de estudo. $\mathrm{Na}$ visão do autor, o estudo de caso é útil onde entender o impacto do contexto organizacional 
e ambiental, nos processos sociais, é importante. Sendo assim, como nos propomos a investigar qual a concepção dos alunos do curso de Letras-Inglês acerca de seu papel e como o contexto formativo deles colabora para a construção de tal concepção, a estratégia de pesquisa escolhida nos pareceu a mais sensata.

Os dados foram colhidos através de um questionário aberto com as seguintes perguntas:

1. O que você entende por professor transmissor? E professor mediador de conhecimento?

2. Qual das perspectivas acima é enfatizada em seu curso? Como ela é enfatizada?

3. Com qual perspectiva de atuação (transmissor ou mediador) você pretende atuar ou já atua?

4. Por que a perspectiva escolhida é a ideal para o ensino/aprendizagem de L.E?

Participaram da pesquisa quatro alunos que estavam finalizando o Estágio Supervisionado 3, sendo dois do sexo masculino e duas do feminino. No entanto, apenas três deles foram até o fim da pesquisa. Todos os participantes foram orientados a colocarem pseudônimos nos questionários com a finalidade de terem suas identidades resguardadas. A escolha desses participantes se justifica, pois por estarem finalizando a graduação, espera-se que eles já tenham entrado em contato com discussões acerca de seus papéis enquanto docentes.

\section{ANÁLISE DE DADOS}

$\mathrm{Na}$ presente seção, iremos discutir os dados coletados. Como nos objetivamos a investigar a concepção dos participantes em relação a seus papéis como professor de língua estrangeira, mais especificamente, sobre a função de transmissor ou mediador, achamos importante indagar qual a visão dos participantes sobre os termos. Abaixo temos a fala de Ethan, Jack e Helena.

O professor transmissor seria aquele que apenas expõe o conhecimento diante de sua turma e espera que os alunos receba-o, observe e aprenda. Creio que o professor transmissor não leve em consideração fatores afetivos, que muito influenciam o ambiente de aprendizagem, ou o estilo individual ou o tempo com que cada aluno aprende. E mais importante, esse professor ao apenas transmitir o conhecimento, talvez não considere o contexto no qual os alunos se inserem. Por outro lado, o professor mediador, creio eu, leva em consideração o conhecimento já possuído pelo aluno, seu potencial, sua afetividade e crenças acerca do conhecimento alvo e ajuda esse aluno a chegar lá. Seria esse professor como uma ponte entre o aluno/conhecimento real e potencial. Acredito que uma palavra chave para o professor 
mediador seja "autonomia". O professor mediador ensina e mostra ao seu aluno sua própria capacidade de aprender. (Excerto 1 - Questionário aberto respondido por Ethan)

Transmissor é aquele que apenas mostra o que é certo e errado. $\mathrm{O}$ mediador estimula o aluno na busca pelo saber, ajudando na autonomia do aluno. (Excerto 2 Questionário aberto respondido por Helena)

Ambos compartilham do mesmo campo de trabalho, porém um se dedica a formar alunos para satisfazer a necessidade do mercado (professor transmissor) e o outro procura formar profissionais para várias áreas de atuação, auxiliando-o a entender de fato o conteúdo, o conteúdo tanto na teoria quanto na prática, se dedica a ajudar o aluno a entender o que está sendo de fato ensinado. (Excerto 3 - Questionário aberto respondido por Jack)

É notório pela fala de Ethan que suas concepções sobre a função docente dialogam bastante com o que é enfatizado pela teoria sociocultural. O participante aponta que professor transmissor é aquele cuja finalidade estaria ligada à exposição de conhecimento na qual o aluno não teria nenhum engajamento ativo. O papel que o participante atribui ao professor transmissor está em sintonia com o que foi postulado por Pereira (1999). O pesquisado acredita que o professor transmissor não leva em consideração fatores extra verbais como a afetividade, o estilo, tempo e contexto de cada aluno. Sua visão de professor mediador entra em sintonia com o que é proposto por autores de nossa fundamentação teórica como Paiva (1998), Weininger (2008) e Figueiredo (2006). O professor mediador tem o papel de ajudar o aluno a alcançar seus objetivos.

É evidente também que o participante apresenta conhecimento sobre a teoria vygostskyana em relação ao papel da mediação na aprendizagem. Ethan afirma que o professor é o intermédio entre o conhecimento real e o potencial do aluno, sendo o docente o responsável por ajudar o aprendiz a alcançar o que está em sua potencialidade. $\mathrm{O}$ discurso do pesquisado aqui entre em sintonia com as postulações de Zona de Desenvolvimento Proximal, proposta por Vygotsky (1998).

Helena é enfática ao dizer que o professor transmissor é aquele cuja atividade estaria ligada ao ensinar o que é certo e errado e nada mais, ou seja, a participante entende que esse modelo de professor atua de forma limitada. Assim como Ethan, a participante acredita que o professor mediador deve ajudar o aprendiz na busca pelo saber.

Jack acredita que, no mercado de trabalho, ainda existam os dois tipos de professores, a diferença, para ele, recairia em tal contexto. Enquanto o professor transmissor é aquele que 
atende uma demanda do mercado, o professor mediador seria aquele que está disposto a ajudar o aluno a entender o que é ensinado, trabalhando tanto na teoria quanto na prática.

Com os trechos em análise, podemos concluir então que os participantes entendem o professor transmissor como um profissional cuja função seria limitada e não inclusiva, pois o aluno não teria nenhum engajamento ativo no processo de aprendizagem. Já o mediador, é visto pelos três participantes como aquele cujo principal objetivo seria ajudar o aluno, principalmente na busca pela autonomia, conforme apontam, especificamente, Ethan e Helena.

Como nos propomos a investigar qual das funções mencionadas acima é enfatizada ao longo da formação dos futuros professores, analisaremos, em seguida, na visão dos participantes, com qual perspectiva o curso de Letras que estão inseridos corrobora. Ao serem questionados qual dos modelos de atuação é enfatizado, obtivemos as seguintes respostas:

Creio que a perspectiva enfatizada em meu curso seja a de professor mediador, pois percebo em nossas aulas que sempre ocorrem discussões abertas sobre os temas propostos. Os professores têm a preocupação de criarmos a nossa própria opinião sobre os temas discutidos e sobre as pessoas que lemos. Na sala de estágio é sempre enfatizado a autonomia, contexto social, conceitos que um professor mediador deve levar em conta. (Excerto 4 - Questionário aberto respondido por Ethan)

Essa pergunta é um tanto subjetiva visto que cada professor tende a ter um comportamento diferente em sala de aula de tal forma que tanto há professores transmissores quanto mediadores do conhecimento. (Excerto 5 - Questionário aberto respondido por Jack)

Professor mediador. O professor destaca pontos importantes e a partir disso buscamos por conta própria o conhecimento a fundo. (Excerto 6 - Questionário aberto respondido por Helena)

A partir dos trechos, é possível constatar que, para Helena e Jack, o contexto de formação no qual ambos estão inseridos enfatiza o papel do professor enquanto mediador. Concordamos com Bohn (2005) ao enfatizar o papel da Universidade na formação de professores. Quando tal instituição proporciona um ensino reflexivo e crítico, isso certamente terá impacto na atuação dos profisssionais da educação.

É notável, também, que, para Helena e Jack, o modo como seus professores ministram as aulas, considerando contextos, dando espaço para suas falas e promovendo a autonomia faz parte da identidade de um professor mediador. Vemos aqui muitas similaridades com o que foi 
postulado por Hall e Walsh (2002) que veem benefícios nas interações onde professores incorporam as falas dos alunos.

Jack, no entanto, aponta um fato curioso, uma vez que, para ele, os professores tendem a ter comportamentos pedagógicos diferentes, sendo possível inferir que ao longo da sua jornada acadêmica já se deparou tanto com professores transmissores quanto mediadores.

Analisaremos agora a terceira pergunta de nosso questionário. Perguntamos aos participantes com qual das perspectivas eles pretendem atuar no ensino, ou caso já autem, qual delas faz parte de sua prática pedagógica.

\begin{abstract}
Eu já atuo como professor e tento atuar como professor mediador da melhor maneira que sei. No curso privado de inglês, percebo que é mais fácil atuar como mediador devido ao número menor de alunos e as suas motivações por estarem ali. Por outro lado, na escola pública (cerca de quarenta alunos por sala) confesso que em certos momentos, por ter que cumprir conteúdos e um calendário, acabo me tornando transmissor. Tento, através de atividades e aulas mais discursivas fazer com que os alunos produzam e percebam que eles mesmos, através de seus interesses, podem tornar o aprendizado de Inglês agradável. Apesar das condições de trabalho não contribuírem muito, pretendo continuar atuar como mediador (Excerto 7 Questionário aberto respondido por Ethan)
\end{abstract}

Já atuo como professor e pretendo me formar professor mediador a fim de estender o conhecimento adquirido ao longo dos anos para um público engajado a ensinar e aprender a língua específica de minha formação. (Excerto 8 - Questionário aberto respondido por Jack)

Não pretendo atuar na área, mas se atuasse gostaria de ser um professor mediador. (Excerto 9 - Questionário aberto respondido por Helena)

Ethan e Jack já atuam como professores, ao contrário de Helena que, na verdade, nem pretende ministrar aulas, mas caso o fizesse gostaria de exercer a função de mediadora. Percebemos pela fala de Ethan que, para ele, existem influncias diretamente ligadas aos contextos de ensino que fazem com que haja uma mudança no papel do professor. $\mathrm{O}$ participante revela que, no curso privado de idiomas, ser mediador é mais fácil por ter uma quantidade reduzida de alunos e estes possuírem motivação para estarem aprendendo a línguaalvo. Ele diz que na escola pública, ser mediador se torna um pouco mais complicado por conta dos cronogramas de conteúdos que devem ser trabalhados ao longo do ano letivo, além disso, Ethan atribui a quantidade grandiosa de alunos como um fator que faz com que professores atuem como transmissores. Entretanto, por mais que existam coerções externas influenciando o papel do professor, Ethan revela que ainda quer continuar com a perspectiva mediadora. Jack 
entra em sintonia com Ethan, pois, também, já atua como professor e espera exercer a função mediadora cada vez mais.

Partindo para a última pergunta do questionário, nos objetivamos a investigar por que a perspectiva escolhida pelos participantes é a ideal para o processo de ensino/aprendizagem de L.E.

\begin{abstract}
Acredito que tornar o conhecimento significativo para o aluno seja essencial. Ele deve olhar para a língua inglesa em minha aula e de alguma forma relacionar com a sua vida para que então ele queira por si só alcançar aquilo. Ainda mais se tratando de língua estrangeira, o professor mediador deve quebrar certas crenças e trabalhar a autoestima de seus alunos. Eu acredito que aprender uma língua nova depende em grande parte do aluno, e só do professor ajudar a modificar a suas crenças em relação à língua e fazer ele se sentir capaz de aprender, uma grande porta para a autonomia é aberta. Por essas razões creio que atuar como mediador seja ideal (Excerto 10 Questionário aberto respondido por Ethan)
\end{abstract}

Porque é de grande responsabilidade do professor se certificar que o aluno desenvolva atributos, que o faça questionar sobre o que está aprendendo...tendo em vista formar alunos com conhecimento que vão além das quatro habilidades[...] (Excerto 11 Questionário aberto respondido por Jack)

Entendo que a perspectiva de atuação do mediador ajuda mais o aluno a buscar o que ele realmente sobre determinado assunto em L.E (Excerto 12 - Questionário aberto respondido por Helena)

Ethan diz que atuar como mediador é o ideal, pois adotando esta postura o ensino será significativo para o aluno. O participante defende que ser mediador faz com que certos bloqueios, causados por crenças de alunos, sejam quebrados. Jack revela que ser mediador faz com o que o professor se engaje em um ensino reflexivo no qual os alunos irão questionar o que estão aprendendo e isso é de grande responsabilidade do docente. Já Helena revela que o papel do mediador é o adequado uma vez que só assim o professor poderá ajudar o aluno na busca pelo conhecimento.

\title{
6. CONCLUSÃO
}

Conforme apontamos no início deste artigo, a linguagem tem um papel crucial no ensino/aprendizagem de uma língua estrangeira, pois a utilizamos para construir conhecimento em interação com outros, sendo estes mais experientes ou não de acordo com a teoria sociocultural. O modo como professores interagem com seus alunos é um grande fator a se 
REVISTAELETRÔNICA DE GRADUAÇÃO

EPÓS-GRADUAÇÃO EMEDUCAÇĀO

REJ/UFG
REFLETIONIS

NÜMERO ESPECIAL VOL. $15 \mathrm{~N}^{-2} 212019$

considerar na construção do conhecimento, principalmente o linguístico já que esta é uma atividade metalinguística.

O professor deve envolver o aluno no processo de aprendizagem, maximizando suas oportunidades de interação, ou seja, deve concebê-lo como um agente ativo durante todo processo. Portanto, o professor deve ser um mediador do conhecimento. A ênfase em tal papel é de responsabilidade dos cursos de formação de professores, uma vez que o modo como professores interagem com seus alunos está diretamente ligado ao modo como eles acreditam que o ensino deve ser, conforme apontam Hall e Walsh (2002).

Neste artigo, almejamos investigar qual a concepção de discentes do curso de LetrasInglês acerca de seus papéis enquanto mediadores ou transmissores de conhecimento, assim como se eles acreditam que o departamento responsável por sua formação tem contribuído para a visão que adotarão ou já adotam em suas práticas. Além disso, buscamos investigar, também, por quais razões a visão adotada é a ideal no processo de ensino/aprendizagem.

Fica evidente, com a análise dos dados, que os participantes da pesquisa dialogam com a concepção da teoria sociocultural em relação ao papel do professor mediador. É nítido que as definições dos participantes entram em sintonia com o que é proposto pela teoria abordada, que o curso que os formam tem enfatizado tal perspectiva, assim como aqueles que pretendem atuar adotam ou adotarão a postura mediadora do professor que, conforme eles pontuam, deve ajudar o aluno na busca pelo conhecimento.

\section{REFERENCIAS}

ANTÓN, M. The Discourse of a Learner-Centered Classroom: Sociocultural Perspectives on Teacher-Learner Interaction in the Second-Language Classroom. The Modern Language Journal, v. 83, n. 3, p. 303-318, 1999

BOHN, H. I. A formação do professor de línguas - A construção de uma identidade profissional. Investigações (UFPE. Impresso), Recife, Pe, v. 17, n.2, p. 97-113, 2005.

FIGUEIREDO, F. J. Q. de. A aprendizagem colaborativa de línguas: algumas considerações conceituais e terminológicas. In: FIGUEIREDO, F. J. Q. de. (Org.). A aprendizagem colaborativa de línguas. Goiânia: Ed. da UFG, 2006. p. 11-45. 
HALL, J. K.; WALSH, M. Teacher-student interaction and language learning. Annual Review of Applied Linguistics, v. 22, p. 186-203, 2002.

HARTLEY, J. F. Case studies in organizational research. In: CASSELL, C. \& SYMON, G. (Ed.). Qualitative methods in organizational research: a practical guide. London: Sage, 1994. p. $208-229$

LANTOLF, J. P.; APPEL, G. Theoretical framework: an introduction to Vygotskian approaches to second language research. In: LANTOLF, J.; APPEL, G. (Ed.). Vygotskian approaches to second language research. New Jersey: Ablex Publishing Corporation, 1994. p. $1-32$.

OXFORD, R. L. Cooperative learning, collaborative learning, and interaction: Three communicative strands in the language classroom. The Modern Language Journal, v. 81, n. 4, p. 443-456, 1997.

PAIVA, V.L.M.O. Avaliação dos cursos de Letras e a formação do professor. Revista do GELNE, João Pessoa, v. 5, n. 1 e 2. p. 193-200, 2004.

PEREIRA, J.E.D. As licenciaturas e as novas políticas educacionais para a formação docente. Educação \& Sociedade. Campinas. n. 68. p.109-125, 1999.

SWAIN, M.; BROOKS, L.; TOCALLI-BELLER, A. Peer-peer dialogue as a means of second language learning. Annual Review of Applied Linguistics, v. 22, p. 171-185, 2002.

SWAIN, M.; LAPKIN, S. Interaction and Second Language Learning: Two Adolescent French Immersion Students Working Together. The Modern Language Journal, v. 82, n. 3, p. 320-337, 1998.

VAN LIER, L. Inside the Classroom: Learning Processes and Teaching Procedures. Applied Language Learning, v. 2, n. 3, p. 29-68, 1991.

VOLPI, M.T. A formação de professores de língua estrangeira frente aos novos enfoques de sua função docente. In: LEFFA, V.J (Org.). O professor de língua estrangeira: construindo a profissão. Pelotas: EDUCAT, 2008. p. 133-143. 
VYGOTSKY, L. S. A formação social da mente. São Paulo: Martins Fontes, 1998. p. 69-76. VYGOTSKY, L.S. A formação social da mente. 4. ed. São Paulo: Martins Fontes, 1991.

WEININGER, M.J. Do aquário em direção ao mar aberto: Mudanças no papel do professor e do aluno. In: LEFFA, V.J (Org.). O professor de língua estrangeira: construindo a profissão. Pelotas: EDUCAT, 2008. p. 45-74.

WELLS, G. The zone of proximal development and its implication for learning and teaching. In: WELLS, G. (Ed). Dialogic inquiry: Towards a sociocultural practice and theory of education. New York: Cambridge University Press. 